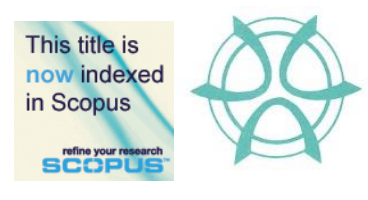

PLANNING MALAYSIA:

Journal of the Malaysian Institute of Planners

VOLUME 16 ISSUE 3 (2018) Page 332 - 343

\title{
HISTORIC BUILDING INFORMATION MODELLING (HBIM) FOR MALAYSIAN CONSTRUCTION INDUSTRY
}

\author{
Maisarah Ali ${ }^{1}$, Kamsiah Mohd Ismail ${ }^{2}$, Khairusy Syakirin Has-Yun \\ Hashim $^{3}$, Saifulnizam Suhaimi ${ }^{4}, \&$ Muhammad Hadi Mustafa ${ }^{5}$ \\ ${ }^{2,3,4,5}$ Kuliyyah of Architecture and Environmental Design \\ ${ }^{1}$ Kuliyyah of Engineering \\ INTERNATIONAL ISLAMIC UNIVERSITY MALAYSIA
}

\begin{abstract}
The Historic Building Information Modelling (HBIM) is widely accepted and practiced all over the world. However, the adoption of HBIM within Malaysian construction industry is relatively low and slow because it demands new skill sets such as 3D modelling expertise, understanding of the approach, a lot of collaboration and it forces industry players to relate to each other differently. It is psychologically a very healthy environment, but not necessarily an easy transition. Since our cultural heritage buildings are limited, it is crucial for us to take care of it. Loss of information, insufficient documentation, poor maintenance, lack of technology adaptation, and reports reliability are among common problems the industry are facing. This paper review the attributes of HBIM based on literature, and its benefits, processes, tools, and challenges are highlighted. From this study, HBIM shows significant attributes that can contribute in providing a better understanding in handling historical buildings, besides allowing enhanced communication and documentation.
\end{abstract}

Keywords: Historic Building Information Modelling, attributes, benefits, challenges, Malaysia 
PLANNING MALAYSIA

Journal of the Malaysia Institute of Planners (2018)

\section{INTRODUCTION}

Historic Building Information Modelling (HBIM) is the evolution of Building Information Modelling (BIM). BIM is an approach that gets people and information working together effectively and efficiently (Antonopoulou, 2017; Abdul Shukor, Wong, Rushforth, Basah, \& Zakaria, 2015; Volk, Stengel, \& Schultmann, 2014). The idea of HBIM arises from the BIM approach which has been a popular topic of discussion within construction industry worldwide. Instead of focusing on newly build construction, adopting the technological approach for historical building is widely considered all around the world. In European countries such as England and Ireland, HBIM approach has been applied on some of the country's heritage buildings such as Imperial War Museum and Woodseat Hall in Staffordshire (Antonoupoulou, 2017). In the United Kingdom, an organization called Historic England spearheads many conservation works of the country's heritage buildings by adopting this approach. In Italy, there are buildings such as the San Cipriano Church and St. Maria Church, which have been taken as HBIM case studies (Continenza, Redi Savini, Tata, \& Trizio, 2018) to move forward with their culturally rich Roman buildings. In Turkey, there is an increasing awareness via summits and discussion to preserve Ottoman's empire architectural heritage within the region using the approach. The organizations in these countries are using HBIM because they believed that HBIM has many benefits. It gives great value in the future, more efficient and promotes technological relevancy (Baik, 2017; Logothetis, Delinasiou, \& Stylianidis, 2015; Abdul Shukor et al., 2015). However, there are no case studies found using HBIM in Malaysian context. This is not surprising since the adaptation of BIM itself is still in infancy for Malaysian construction industry (Zahrizan, Ali, Haron, Marshall-Ponting, \& Hamid, 2013).

Historic buildings are important as they reflect the identity of a nation and culture. In Malaysia, there are only 183 buildings that have been gazetted as national heritage by the authority (Ali et al., 2017). The National Heritage Department or Jabatan Warisan Negara (JWN) is the authoritative body that leads the effort of heritage preservation in Malaysia. According to the Malaysian Heritage Act 2005 (Act 645), these buildings need to be at least 50 years (clause 2.1a) before it can be qualified for registration under the Act. In Malaysia, there are not many buildings with significant values to the country remain entirely operable after 50 years due to deterioration issues (Al-Obaidi, Wei, Ismail, \& Kam, 2017).

Since the number of heritage buildings is limited, it is crucial for us to take care of the traditions and heritage; ensuring its timelessness and safe from any threats (Mohd Yusoff, Dollah, \& Kechot, 2010). Most of the conservation and preservation of these historic buildings are carried out manually by conventional methods where guidelines such as Historical Architecture Building Survey (HABS) are followed by conservationists (Kayan, Akashah, \& Ishak, 
Maisarah Ali, Kamsiah Mohd Ismail, Khairusy Syakirin Has-Yun Hashim, Saifulnizam Suhaimi, \& Muhammad Hadi Mustafa Historic Building Information Modelling (HBIM) for Malaysian Construction Industry

2013). Generally, the standards and documentation process uses papers, pictures, and reports as main output. However, building model is seldom produced as a submission requirement. Loss of information, insufficient documentation, poor maintenance, lack of technology adaptation, and reports reliability are among common problems the industry are facing (Ali et al., 2017; Khodeir, Aly, \& Tarek, 2016; Volk et al., 2014; Harun, 2011).

Fortunately, the recent development in ICT has introduced HBIM as a tool to manage projects related to construction industry effectively and efficiently (Ali et al., 2017). A HBIM model can store information of any historic building and allow continuity of information sharing among stakeholders (Khodeir et al., 2016; Volk et al., 2014). Among the information that can be stored are the materials used for the building, description of work regarding an element or components of the building, semantics for building elements, manufacturers detail and dimension of building components (Ali et al., 2017; Logothetis et al., 2015). Therefore, this paper discusses how HBIM can benefits towards Malaysian construction industry in relation to using HBIM for heritage buildings.

\section{HISTORIC BUILDING INFORMATION MODELLING (HBIM)}

HBIM is a study using BIM approach on historical buildings. In other words, HBIM is proposed as a new system of modelling historical structures. It is a shared digital representation of physical and functional characteristics of any built object, which forms a reliable basis for decision-making during its life-cycle (Murphy, McGovern, \& Pavia, 2013). HBIM is a semantic-aware database of historical buildings, in which the geometric model is connected to descriptive multi-source information. Semantic-aware database refers to the model's capability to store information within it and able to connect to other sources. HBIM is also described as a novel system to automatically produce visualization models and preservation of documents (Dore \& Murphy, 2017).

HBIM is a project simulation consisting of the $3 \mathrm{D}$ models of the historic building's components with links to all required information including the description about individual components and its nature. In many cases, this denotes a beginning of a new approach where the details about historical components can be shared and communicated visually, which has previously only been available to persons who could 'read plans' (Continenza et al., 2018; Antonoupoulou, 2017). In essence, HBIM can be used as an archive, information resource and acts as a management tool to aid future investigations on projects and research (Baik, 2017; Volk, et al., 2014; Murphy et al., 2013). HBIM demands skillsets such as 3D modelling expertise, understanding of the approach, a lot of collaboration and it encourages industry players to relate to each other differently (Continenza et al., 2018; Antonoupoulou, 2017; Abdul Shukor et al., 2015). Up until now, Malaysian government through Construction Industry and Development Board (CIDB) and Public Work Department (PWD) plays an active 
role in encouraging construction players to embark BIM approach for their projects. The relevant bodies have made some significant initiatives such as organizing seminars, providing affordable series of training and establishing a reference center in Kuala Lumpur for the industry to refer. The approach is believed to help in increasing efficiency among practitioners, reducing operating cost and improving sustainability. Although the potential for HBIM to be implemented in Malaysian construction industry is still up in the air, it has been proven to provide efficient and productive outputs in other countries (Antonoupoulou, 2017; Baik, Boehm, \& Robson, 2013; Zahrizan et al., 2013). Hence, as for our initial step, it would be recommended to embark on HBIM in term of existing BIM framework.

\section{ATTRIBUTES OF HBIM}

In practicing HBIM, one needs to think on the building's representation to simulation process by considering 'all-in-one' analysis consisting of geometry, semantics, and information of the historic building (Dore \& Murphy, 2017). Since HBIM is beyond simple illustration, a HBIM practitioner needs to be able to describe the object and the relationship within the structure. Nevertheless, for better understanding, authors have come up with the following attributes about HBIM:

\section{1- Able to store information about the building components}

Since HBIM model can act as a semantic-aware database which refers to its capability to store information within it, therefore, it can be connected with other sources and information such as the material used, manufacturer's detail and relevant data can be seen clearly and shared effectively (Khodeir et al., 2016). HBIM platforms being used currently in the industry are similar to BIM platforms provided by software providers such as Autodesk, ArchiCAD, Tekla and Bentley since they offer almost similar functionalities. The functionalities and capability to store and display intangible data such as material's type, the name of the component, dimension, models and other relevant information; apart from the visual shape of the form can be viewed from a platform such as Autodesk A360's.

\section{2- HBIM allows a clear and reliable visual display}

HBIM allows a clear and reliable visual display since the historical building is constructed in 3-dimensional (3D) using its tool. This eliminates the problem of drawings misinterpretation that sometimes happen in the industry (Abdul Shukor et al., 2015). A 3D model gives its stakeholder a better view on how the building looks like. Figure 1 shows a complete architectural model of Balai Besar Alor Star that has been modelled into an HBIM environment. 
Maisarah Ali, Kamsiah Mohd Ismail, Khairusy Syakirin Has-Yun Hashim, Saifulnizam Suhaimi, \& Muhammad Hadi Mustafa Historic Building Information Modelling (HBIM) for Malaysian Construction Industry
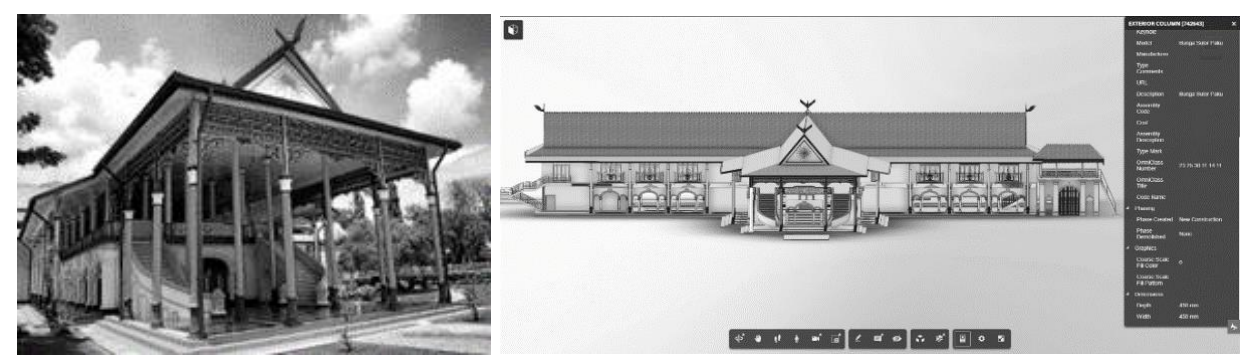

Figure 1: Balai Besar in HBIM environment Source: Authors (2017)

\section{3- Able to define building components into its elements}

HBIM permits better understanding about a component's nature in terms of its element and sub-elements (Baik, 2017; Baik, Alitany, Boehm, \& Robson, 2014). It allows the practitioner to deconstruct and reassemble historical components for a better understanding of its nature. Example of this feature is shown in Figure 2.
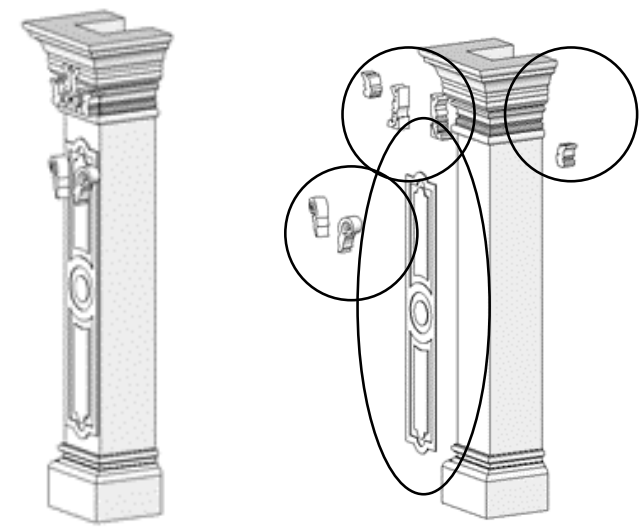

Figure 2: Example of Balai Besar Alor Star component's assemblies Source: Authors (2017)

\section{4- Automation for documentation and reference}

Since the process of components creation will create a library of various components which contains elements and its sub-elements, the HBIM platform also enables information to be studied and inserted as valuable information (Beck, 2013). This information can be used for documentation purpose and also act as the reference for every stakeholder (Noor et al., 2017). Figure 3 shows an example on how the breakdown of a component creation will help in the understanding of the nature of the component itself. This will allows a better understanding on the building as a whole. 
PLANNING MALAYSIA

Journal of the Malaysia Institute of Planners (2018)

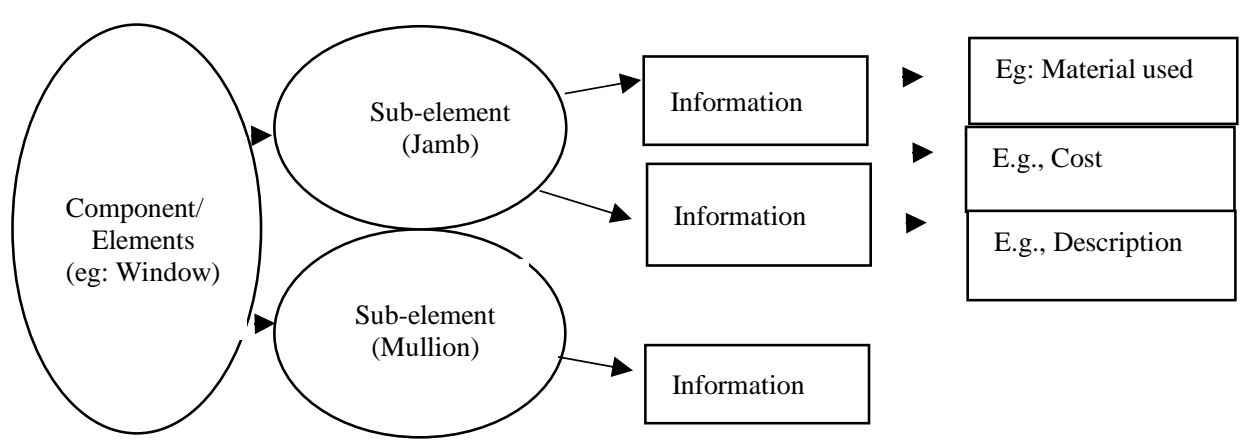

Figure 3: Example of component (Window)

\section{MAIN BENEFITS OF HBIM}

This research seeks the potential of the applications of BIM in the heritage sector (HBIM). It may vary according to the scope and purpose of a project with the considerations below:

\section{1-Documentation}

Most historical buildings worldwide have complex geometry, ornamentation, and woodcarving. Thus 3D documentation is the most appropriate method to capture every detail (Quattrini, Malinverni, Clini, Nespeca, \& Orlietti, 2015). This documentation in a digital archive creates a collection of historical data, information and different types of design shall result in automated documentation of precise preservation and conservation of heritage (Baik et al., 2013). HBIM also allows the integration of the digital representation for the building lifespan. These data will accelerate the acquisition process and improves the accuracy of the repository (Beck, 2013).

\section{2-Simulation for Planning}

In terms of design simulation such as sun path, structural reliability, and other tests can be performed quickly and may act as the reference benchmarks for planning (Antonoupoulou, 2017). This platform enables faster and cost-saving method in keeping track of the environmental performance of the historical building. Other simulation capabilities that are available include energy analysis, structural analysis, and scenario analysis (Khodeir et al., 2013). Scenario analysis refers to the ability of HBIM model to represent distinct periods; which allows the establishment of a sequence of building evolution and condition.

\section{3-Communication}

In HBIM, the communication between stakeholders can be made simpler, faster and easier to be shared with themselves (Continenza et al., 2018; Ali et al., 2017). HBIM model can support 'live update' if someone is modifying the model. It is instantaneously shared, and the data can be used commonly among relevant 
Maisarah Ali, Kamsiah Mohd Ismail, Khairusy Syakirin Has-Yun Hashim, Saifulnizam Suhaimi, \& Muhammad Hadi Mustafa Historic Building Information Modelling (HBIM) for Malaysian Construction Industry

parties. For example, if the client gave a review on the model, a modeller can instantly change it on the platform. Thus, it allows communication through utilization and sharing of information.

It is more effective to coordinate a building using a visual approach with a 3D model, so that the location and relationships of all the components and their potential conflicts can be resolved while still in the planning phase (Baik, 2017; Ali et al., 2017; Abdul Shukor et al., 2015). This also mitigates potential conflict where plan drawings do not provide visual clue about the height of any drawn components, which normally need to be visualized from the study of several drawings and written information. In short, these advantages can be used in many occasions such as in conservation planning, condition monitoring, preventive maintenance, asset management, intervention options appraisal, work programming, construction simulation, disaster preparedness and project security (Ali et al., 2017; Baik et al., 2013; Del Giudice \& Osello, 2013).

Other than that, in Malaysian interest, HBIM has substantial value in preservation and conservation of historical and heritage buildings. As the vital drive, the Federal government needs to be an early adopter of HBIM technology. Among benefits of HBIM adoption are (Continenza et al., 2018; Antonopoulou, 2017; Abdul Shukor et al., 2015; Volk et al., 2014):

- Increase understanding on heritage buildings;

- Creating more jobs opportunities;

- Increases productivity;

- Better documentation and reliable storage information of historical buildings;

- Better facilities management;

- Technology relevancy; and

- Provides a way of transmitting knowledge to the future generation.

Nonetheless, upon HBIM completion, the model can be used for future purposes such as reuse, monitoring, replication, reconstruction, 3D printing and even for gaming and tourism development (Continenza et al., 2018; Antonoupoulou, 2017). However, there is an urgent need to develop a shared interoperable historical building objects library, to enable an improved and more efficient future HBIM projects to be accomplished (Baik et al., 2014).

\section{HBIM PROCESS}

Generally, HBIM process consists of 2 stages as shown in Figure 4. In the first stage, is the data collection phase activity called the 'learning phase' where data regarding the building is collected using few methods. Activity such as data collection needs to be carried out to have a better understanding regarding the historical building (Baik, 2017). This stage 1 is mainly to gather the tangible data such as length, width, height and other relevant information. However, data such 
PLANNING MALAYSIA

Journal of the Malaysia Institute of Planners (2018)

as dimensions will be used later in the 'second phase' in Stage 2. These dimensions will be in the digital reconstruction phase or the modelling based on the data collected. After the model is completed, an analysis and semantic enrichment will take place in the 'third phase'. A strategic approach to organize these data and metadata is crucial in this phase. Lastly, the 'fourth phase' involves the integration of the HBIM project for the client. In this phase, it might require different delivery requirement depending on the client's needs. Phase 2 to 4 is the processing stage, and its objective is to store and to utilize the information gathered.

\section{Stage 1 (Data Collection) \\ Learning phase (Phase 1) \\ Example of activity: collecting data}

\section{Stage 2 (Processing)}

Digital reconstruction phase (Phase 2)

Example of activity: modelling

Analysis and Semantic enrichment phase (Phase 3)

Example of activity: Organizing data and metadata

Integration phase (Phase 4)

Example of activity: delivery

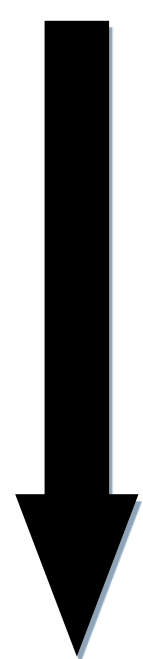

Figure 4: Process of HBIM in stages

\section{HBIM TOOLS}

HBIM tools are equipment and software that are used to facilitate and execute the process flow to enhance the workability of the process (Ali et al., 2017; Quattrini et al., 2015). HBIM tools are generally divided into two complementary objectives; (1) to capture tangible data (2) to stores intangible data. The paragraphs that follow will describe tools for HBIM.

Nowadays, the most popular method used to capture dimension, forms, and typology of the building is known as Terrestrial Laser Scanning (TLS) (Quattrini et al., 2015). TLS is a high-end equipment that helps to capture data in the form of point clouds within a very short period of time. The point cloud is a set of data points in a 3-dimensional coordinate system usually defined by X, Y, and $\mathrm{Z}$ coordinates. Point cloud files support the design process by providing the real-world context where you can recreate the referenced objects or insert additional models (Murphy et al., 2013). Figure 5 shows an example of data collection using this method. The conventional method is by taking the 
Maisarah Ali, Kamsiah Mohd Ismail, Khairusy Syakirin Has-Yun Hashim, Saifulnizam Suhaimi, \& Muhammad Hadi Mustafa Historic Building Information Modelling (HBIM) for Malaysian Construction Industry

measurement using a tape measure or laser measurement before the details obtained is converted into drawings, but this method will take a longer time to arrive at the final data collection (Noor et al., 2017).

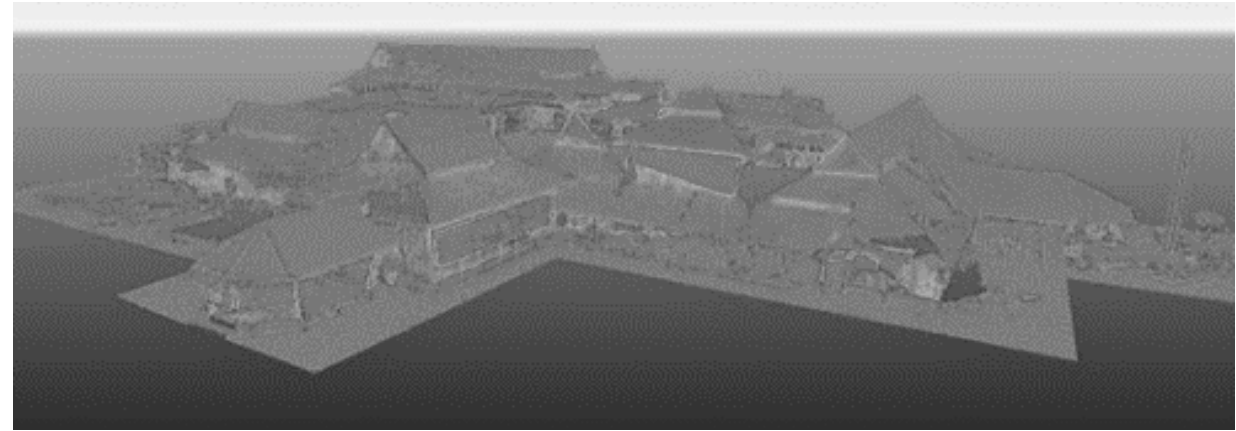

Figure 5: Example of data collection using Terrestrial Laser Scanning tool for HBIM Source: Authors (2017)

For the second objective, there are modelling software provider that are active in the market nowadays such as Autodesk, Bentley, Glodon, Tekla, Graphisoft, Ecodomus, and Vico (Baik et al., 2014). Among favourite tools being used are Autodesk Revit, Autodesk Structure, Bentley Facilities, Tekla Structures, Gehry Digital MEP and Naviswork. Each tool provider provide many different tools as it has its functions to manage various activities in projects related to the construction industry. Usually, the selection of the tools is based on four (4) features, which are reliability on communication and data exchange, accuracy, and usability (Baik et al., 2013). The selection of tools to be used for a specific project may also vary depending on the scope and background of the work to ensure a successful output.

\section{CHALLENGES IN HBIM}

Despite the promising benefits of HBIM, some challenges are unavoidable. Among the common challenges in implementing HBIM are insufficient experts to execute the process, expensive tools and training, low commitment and awareness from the stakeholders view to invest for historical buildings (Dore \& Murphy, 2017; Gardezi, Shafiq, Nurudinn, Farhan, \& Umar, 2014; Volk, et al., 2014).

However, one of the most significant challenges for HBIM approach is documenting the building in terms of BIM functionality. This is because many information about historical building has been lost and some are impossible to retrieve thus, creating data void problems (Antonopoulou, 2017; Baik et al., 2014; Beck, 2013). Although BIM functionalities help in improving attribution of HBIM, but this is useless if no information regarding the historical building is available. Therefore, the primary challenge lies in the techniques in getting the 
information to minimize data voids in the process.

Data voids have implications in the modelling process, where the level of development (LOD) for HBIM might not reach the highest LOD, thus making the model 'incomplete.' In HBIM modelling process, there are two types of information involved, known as tangible and intangible information (Volk et al., 2014). Tangible is information about shape, forms, and whatever perceptible by touch and can be physically measured, whereas intangible is information that is physically untouchable such as the description of the material used for the element that gives value to it. Therefore, in the modelling process, accuracy, complexity, and reliability of data are important. Commonly, HBIM process gives challenges in three major areas known as accuracy, complexity, and reliability (Dore \& Murphy, 2017). In handling this concern, tools such as TLS and modelling software plays a vital part in minimizing this problem. For data voids, some practitioners suggest that educated guesses may have to be made about certain aspects of the asset's information (Baik, 2017; Ali et al., 2017). However, all information (delivered/exchanged) must be verified and validated, allowing zero ambiguity.

It is recommended that in HBIM process, any part of the model is based on assumption due to data voids or incomplete information should be explicitly marked to avoid ambiguity and future confusion, misinterpretation and illinformed decision-making (Antonouloupou, 2017; Baik, 2017). An approach to validating these data can be made later through 'expert opinion' method.

\section{CONCLUSION}

The Historic Building Information Modelling (HBIM) has been acknowledged by many kinds of research to be useful to develop a system for maintaining a historical building efficiently. Its attributes which enable big data storage and reuse of information along with capability of acting as domain knowledge throughout the lifecycle of a building has made it very popular. Extensive encouragement to use HBIM in the industry can help to expand the overall initiatives and strengthen the image of the Malaysian industry. Besides, looking at current government efforts for BIM, it is anticipated that HBIM technology will likely be used for many other types of projects in the future. Lastly, it is also recommended that further research on this area be performed for a better addition to the body of knowledge for Malaysia's chapter.

\section{ACKNOWLEDGMENT}

This research is supported by a grant (TRGS16-03-003-0003) from the Ministry of Higher Education Malaysia (MOHE). This research is also supported by Kuliyyah of Architecture and Environmental Design (KAED) and Kuliyyah of Engineering of International Islamic University Malaysia. 
Maisarah Ali, Kamsiah Mohd Ismail, Khairusy Syakirin Has-Yun Hashim, Saifulnizam Suhaimi, \& Muhammad Hadi Mustafa Historic Building Information Modelling (HBIM) for Malaysian Construction Industry

\section{REFERENCES}

Abdul Shukor, S. A., Wong, R., Rushforth, E., Basah, S. N., \& Zakaria, A. (2015). 3D terrestrial laser scanner for managing existing building. Jurnal Teknologi, 76(12), 133-139.

Ali, M., Ibrahim, M. N., Mohd Yunus, R., Yahya, M. R., Ismail, F., Mohd Din, A, \& Ibrahim, M. S. (2017). Exploring methods of quantity measurement for heritage conservation works. Journal of Computational and Theoretical Nanoscience, 23(7), 6277-6280.

Al-Obaidi, K., Wei, S., Ismail, M., \& Kam, K. (2017). Sustainable building assessment of colonial shophouses after adaptive reuse in Kuala Lumpur. Buildings, 7(4), 87.

Antonopoulou, S. (2017). BIM for heritage: Developing a Historic Building Information Model. (n.p.): Historic England.

Baik, A., Boehm, J., \& Robson, S. (2013). Jeddah historical building information modeling "JHBIM" Old Jeddah - Saudi Arabia. ISPRS - International Archives of the Photogrammetry, Remote Sensing and Spatial Information Sciences, XL-5/W2, 73-78.

Baik, A., Alitany, A., Boehm, J., \& Robson, S. (2014). Jeddah Historical Building Information Modelling "JHBIM"; Object Library. ISPRS Annals of Photogrammetry, Remote Sensing, and Spatial Information Sciences, II-5, 4147.

Baik, A. (2017). From point cloud to Jeddah Heritage BIM Nasif Historical House Case study. Digital Applications in Archaeology and Cultural Heritage, 4, 1 18.

Beck, L. S. (2013). Digital documentation in the conservation of cultural heritage: Finding the practical in best practice. ISPRS - International Archives of the Photogrammetry, Remote Sensing, and Spatial Information Sciences, XL5/W2, 85-90.

Continenza, R., Redi F., Savini, F., Tata, A., \& Trizio, I. (2018). HBIM for the archaeology of standing buildings: Case study of the Church of San Cipriano in Castelvecchio Calvisio (L'Aquila, Italy). In P. Fogliaroni, A. Ballatore, \& E. Clementini (Eds.), Proceedings of Workshops and Posters at the 13th International Conference on Spatial Information Theory (COSIT 2017) (pp. 315-324). Cham: Springer.

Del Giudice, M., \& Osello, A. (2013). BIM for cultural heritage. ISPRS - International Archives of the Photogrammetry, Remote Sensing, and Spatial Information Sciences, XL-5/W2, 225-229.s

Dore, C., \& Murphy, M. (2017). Current state of the art historic building information modelling. ISPRS - International Archives of the Photogrammetry, Remote Sensing and Spatial Information Sciences, XLII-2/W5, 185-192.

Gardezi, S. S. S., Shafiq, N., Nurudinn, M. F., Farhan, S. A., \& Umar, U. A. (2014). Challenges for implementation of building information modeling (BIM) in Malaysian construction industry. Applied Mechanics and Materials, 567, 559564.

Harun, S. N. (2011). Heritage building conservation in Malaysia: Experience and challenges. Procedia Engineering, 20, 41-53. 
Kayan, B., Akashah, F. W., \& Ishak, N. H. (2013, November). Conservation Plan for Historic Buildings from Building Control Administration Perspective. The $3^{\text {rd }}$ International Building Control Conference 2013. Nvember 21, 2013, Kuala Lumpur, Malaysia.

Khodeir, L. M., Aly, D., \& Tarek, S. (2016). Integrating HBIM (Heritage Building Information Modeling) tools in the application of sustainable retrofitting of heritage buildings in Egypt. Procedia Environmental Sciences, 34, 258-270.

Logothetis, S., Delinasiou, A., \& Stylianidis, E. (2015). Building information modelling for cultural heritage: A review. ISPRS Annals of Photogrammetry, Remote Sensing, and Spatial Information Sciences, II-5/W3, 177-183.

Mohd Yusoff, M. Y., Dollah, H., \& Kechot, A. S. (2010). Pembangunan warisan di Malaysia: Tinjauan umum tentang dasar. Jurnal Melayu, 5, 277-283

Murphy, M., McGovern, E., \& Pavia, S. (2013). Historic building information modelling - Adding intelligence to laser and image-based surveys of European classical architecture. ISPRS Journal of Photogrammetry and Remote Sensing, 76, 89-102.

Noor, N. M., Kamarudin, Z., Abdullah, A., Aiman, A., Mustafa, M. H., Art, A., ... \& Design, E. (n.d.). Using terrestrial laser scanner for Malay heritage documentation : preliminary approach to Istana Balai.

Quattrini, R., Malinverni, E. S., Clini, P., Nespeca, R., \& Orlietti, E. (2015). From TLS to HBIM: High quality semantically-aware $3 \mathrm{~d}$ modeling of complex architecture. International Archives of the Photogrammetry, Remote Sensing and Spatial Information Sciences - ISPRS Archives, 40(5W4), 367-374.

Volk, R., Stengel, J., \& Schultmann, F. (2014). Building information models (BIM) for existing buildings - Literature review and future needs. Automation in Construction, 38, 109-127.

Zahrizan, Z., Ali, N. M., Haron, A. T., Marshall-Ponting, A., \& Hamid, Z. A. (2013). Exploring the barriers and driving factors in implementing building information modelling (BIM) in the Malaysian construction industry: A preliminary study. Journal - The Institution of Engineers, Malaysia, 75(1), 110 